\title{
MEMONITOR KUALITAS PEMBELAJARAN DI FAKULTAS MATEMATIKA DAN ILMU PENGETAHUAN ALAM UNIVERSITAS UDAYANA
}

\author{
Rahmad Widodo $^{1 \S}$, I Putu Eka Nila Kencana ${ }^{2}$, Ni Luh Putu Suciptawati ${ }^{3}$ \\ ${ }^{1}$ Program Studi Matematika, Fakultas MIPA-Universitas Udayana [Email: rahmadwidodo012000@gmail.com] \\ ${ }^{2}$ ProgramStudi Matematika, Fakultas MIPA-Universitas Udayana [Email: i.putu.enk@unud.ac.id] \\ ${ }^{3}$ ProgramStudi Matematika, Fakultas MIPA-Universitas Udayana [Email: suciptawati@ unud.ac.id] \\ ${ }^{\S}$ Corresponding Author
}

\begin{abstract}
Controlling the quality of learning is very important and influences the accreditation of study programs at the Faculty of Mathematics and Natural Sciences Udayana University, as a guarantor of the quality of graduates. Apply pricipal component analysis to reduce the number of determinant attributes of learning quality, with the aim of looking at the data structure with fewer variables. The $T^{2}$ control chart is a multivariate control chart that is used to view the potrait of the quality of learning in the Mathematics and Natural Sciences Faculty, using new variables obtained from principal component analysis. The results obtained from principal component analysis show that the contribution of the learning quality indicators is univen. The potrait of the quality of learning at the Faculty of Mathematics and Natural Sciences obtained from the individual-moving range (I-MR) and the $T^{2}$ control chart shows the need for corrective actions and monitor regularly to improve the quality of learning.
\end{abstract}

Keywords: Quality control, quality of learning, control chart

\section{PENDAHULUAN}

Universitas Udayana merupakan perguruan tinggi tertua di Provinsi Bali dan memiliki tiga belas fakultas, salah satunya Fakultas MIPA. Enam program studi di Fakultas MIPA empat diantaranya pada tahun 2020 masih terakreditasi B. Akreditasi sangat penting bagi instansi perguruan tinggi, sebagai penjamin kualitas lulusan. Menurut Haramin, et. al. (2019), akreditasi merupakan kegiatan evaluasi yang dilakukan perguruan tinggi berdasarkan standar formal yang telah ditetapkan. Akreditasi memiliki hubungan erat dengan kualitas dan kepuasan mahasiswa pada lembaga perguruan tinggi. Kualitas merupakan kondisi yang tidak pasti atau selalu berubah.

Kualitas dapat diukur dengan melakukan pengendalian kualitas statistika, sebagian besar peneliti menggunakan peta kendali yang hanya memperhatikan satu variabel atau satu karakteristik saja seperti peta kendali rata-rata $(\overline{\mathrm{X}})$, range atau jarak $(\mathrm{R})$, dan individualmoving range (I-MR). Menurut Montgomery (2012), dalam pengendalian kualitas statistika tidak dapat dihindari bahwa jumlah variabel melebihi satu variabel. Analisis komponen utama merupakan metode statistika yang menggunakan metode reduksi peubah, dengan tujuan melihat struktur data dengan peubah yang jauh lebih sedikit, tetapi tanpa banyak kehilangan informasi tentang data keseluruhan (Tabachnick, et. al. 2014). Peta kendali $\mathrm{T}^{2}$ merupakan peta kendali multivariat yang dapat digunakan untuk variabel atau karakteristik dengan jumlah lebih dari satu.

Penelitian tentang kualitas pembelajaran sebelumnya pernah dilakukan oleh Andayani, et. al. (2007), yang bertujuan untuk meningkatkan kualitas pembelajaran pemrograman komputer melalui perkuliahan online. Subjek penelitian tersebut adalah mahasiswa Prodi Matematika FMIPA Universitas Negeri Yogyakarta. Hasil penelitian menunjukkan bahwa terjadi peningkatan kualitas pembelajaran, bahkan mahasiswa mengharapkan digunakan model tersebut untuk kegiatan pembelajaran selanjutnya. Dalam hal ini, untuk menggunakan model tersebut dalam kegiatan pembelajaran 
selanjutnya perlu dilakukan pengendalian kualitas dan memonitor supaya tercapainya hasil yang baik sesuai dengan harapan.

Penelitian tentang pengendalian kualitas menggunakan peta kendali $\mathrm{T}^{2}$ pernah dilakukan Damayanti, et. al. (2016), untuk pengendalian kualitas produksi crude palm kernel oil. Variabel yang diamati meliputi kandungan asam lemak bebas, kadar air, dan cemaran benda asing. Hasil dari penelitian tersebut menunjukkan bahwa proses produksi tidak terkendali. Sehingga perusahaan perlu melakukan tindakan perbaikan yang meliputi proses produksi dan pemantauan berkala untuk menghasilkan produk dengan kualitas yang lebih baik.

Pengendalian kualitas pembelajaran sangat penting dan berpengaruh terhadap akreditasi sebuah instansi perguruan tinggi, sebagai penjamin kualitas lulusan. Karena dimensi penilaian dalam akreditasi diantaranya mutu proses yang mencakup proses pembelajaran, penilaian, dan suasana akademik (Peraturan BAN-PT No.3 Tahun 2019 tentang Instrumen Akreditasi Perguruan Tinggi). Berdasarkan alasan tersebut penulis tertarik melakukan penelitian untuk memonitor kualitas pembelajaran di Fakulas MIPA Universitas Udayana, dengan mengaplikasikan analisis komponen utama untuk mereduksi peubah dan peta kendali untuk melihat potret kualitas pembelajaran. Serta diharapkan dapat dijadikan sebagai rujukan dalam melakukan upaya peningkatan kualitas pembelajaran.

\section{METODE PENELITIAN}

\subsection{Jenis dan Sumber Data}

Data yang digunakan dalam penelitian ini merupakan data primer yang diperoleh dari responden yaitu mahasiswa aktif di Fakultas MIPA. Dimana dalam hal ini terdiri dari enam program studi yaitu Program Studi Biologi, Fisika, Kimia, Matematika, Farmasi, Ilmu Komputer.

\subsection{Variabel Penelitian}

Digunakan variabel kualitas pembelajaran mengadaptasi Standar Sistem Penjamin Mutu Internal Fakultas MIPA Tahun 2020. Meliputi sarana dan prasarana $\left(\mathrm{X}_{1}\right)$, perencanaan pembelajaran $\left(\mathrm{X}_{2}\right)$, proses pembelajaran $\left(\mathrm{X}_{3}\right)$, evalusi/penilaian pembelajaran $\left(\mathrm{X}_{4}\right)$. Indikator pengukuran sebagai berikut:

1. Sarana dan prasarana : ketersediaan fasilitas pendukung pembelajaran $\left(\mathrm{X}_{11}\right)$, sistem informasi layanan proses pembelajaran $\left(\mathrm{X}_{12}\right)$, sistem informasi layanan administrasi $\left(\mathrm{X}_{13}\right)$.

2. Perencanaan pembelajaran : penyampaian kontrak perkuliahan oleh dosen $\left(\mathrm{X}_{21}\right)$, penyampaian tujuan pembelajaran oleh dosen $\left(\mathrm{X}_{22}\right)$, penyampaian bahan ajar/diktat/hand out yang diberikan dosen $\left(\mathrm{X}_{23}\right)$.

3. Proses pembelajaran : dosen berupaya menghidupkan suasana kelas $\left(\mathrm{X}_{31}\right)$, ketepatan waktu pelaksanaan perkuliahan $\left(\mathrm{X}_{32}\right)$, kejelasan penyampaian materi perkuliahan oleh dosen $\left(\mathrm{X}_{33}\right)$, dosen memberikan contoh atau ilustrasi nyata terkait materi $\left(\mathrm{X}_{34}\right)$.

4. Evaluasi/penilaian pembelajaran : dosen memberikan umpan balik terhadap hasil belajar mahasiswa $\left(\mathrm{X}_{41}\right)$, kepuasan mahasiswa terhadap nilai yang diberikan $\left(\mathrm{X}_{42}\right)$.

\subsection{Teknik Pengambilan Sampel}

Pengambilan sampel dilakukan dengan membagi populasi menjadi enam kelompok berdasarkan program studi kemudian diambil sampel dari masing-masing program studi dengan jumlah yang berimbang secara acak (proportionate cluster random sampling). Digunakan rumus Slovin menurut Ryan (2013), yaitu $n=N /\left(1+\left(N \times e^{2}\right)\right)$ dengan galat (e) $7,5 \%$. Kemudian untuk pengambilan sampel masing-masing kelompok berdasarkan proporsi jumlah mahasiswa.

Tabel 1. Jumlah Mahasiswa

\begin{tabular}{l|c|c|c}
\hline \multicolumn{1}{c|}{ Prodi } & $\mathrm{N}$ & Proporsi & $\mathrm{n}$ \\
\hline Biologi & 225 & $10,1 \%$ & 17 \\
\hline Fisika & 281 & $12,5 \%$ & 21 \\
\hline Kimia & 389 & $17,3 \%$ & 28 \\
\hline Matematika & 551 & $24,5 \%$ & 40 \\
\hline Farmasi & 403 & $17,9 \%$ & 30 \\
\hline Ilkom & 399 & $17,7 \%$ & 29 \\
\hline \multicolumn{1}{c|}{ Jumlah } & 2248 & $100 \%$ & 165 \\
\hline
\end{tabular}




\subsection{Metode Analisis Data}

Analisis data dilakukan dengan beberapa tahap sebagai berikut:

1. Pembuatan Kuesioner

Uji validitas dan reliabilitas perlu dilakukan dalam pembuatan kuesioner. Tahap awal dengan penyebaran kuesioner kepada 30 responden. Kuesioner dinyatakan valid apabila nilai $r_{\text {hitung }}>r_{\text {tabel }}$, dan kuesioner dikatakan reliabel apabila nilai Cronbach's Alpha > 0,7 (Hair Jr, et. Al. 2019).

2. Pengumpulan data melalui pengisian kuesioner yang telah dinyatakan valid dan reliabel.

3. Mengamati korelasi antar indikator pada masing-masing variabel dengan memeriksa nilai Bartlett's sphericity untuk mengetahui keeratan hubungan antar indikator yang diamati. Kriteria nilai yang signifikan dari uji Bartlett's sphericity yaitu sig. <0,05.

4. Melakukan analisis komponen utama Analisis komponen utama dilakukan dengan menggunakan software Minitab19 untuk memperoleh nilai eigen dan vektor eigen.

5. Menentukan banyaknya komponen utama Komponen utama yang diambil merupakan komponen utama yang memiliki nilai eigen lebih dari satu.

6. Membuat peta kendali individual-moving range (I-MR) dari masing-masing program studi untuk melihat indikator yang berada di luar batas kendali.

7. Membuat peta kendali multivariat $\mathrm{T}^{2}$ control chart dengan menggunakan nilai taksiran dari komponen utama.

8. Interpretasi hasil dari peta kendali individual-moving range (I-MR) dan peta kendali $\mathrm{T}^{2}$.

\section{HASIL DAN PEMBAHASAN}

\subsection{Uji Validitas dan Reliabilitas Kuesioner}

Pegujian validitas dan reliabilitas kuesioner dilakukan terhadap jawaban responden yang telah disebar kepada 30 responden mahasiswa aktif. Seluruh indikator pertanyaan dinyatakan valid apabila nilai $r_{\text {hitung }}>r_{\text {tabel }}$, dengan nilai $r_{\text {tabel }}$ yaitu 0,361. Kuesioner dikatakan reliabilitas mencukupi apabila nilai Cronbach's Alpha > 0,7 (Hair Jr, et. al. 2019). Pengujian dilakukan menggunakan software Minitab19 diperoleh seperti pada Tabel 2.
Tabel 2. Hasil Uji Validitas dan Reliabilitas

\begin{tabular}{|c|c|c|c|}
\hline Laten & Indikator & $r_{\text {hitung }}$ & $\begin{array}{c}\text { Cronbach's } \\
\text { Alpha }\end{array}$ \\
\hline \multirow[t]{3}{*}{$X_{1}$} & $X_{11}$ & 0,7001 & \multirow{3}{*}{0,8629} \\
\hline & $X_{12}$ & 0,8140 & \\
\hline & $X_{13}$ & 0,7306 & \\
\hline \multirow[t]{3}{*}{$X_{2}$} & $X_{21}$ & 0,8444 & \multirow{3}{*}{0,8827} \\
\hline & $X_{22}$ & 0,7666 & \\
\hline & $X_{23}$ & 0,7373 & \\
\hline \multirow{4}{*}{$X_{3}$} & $X_{31}$ & 0,8508 & \multirow{4}{*}{0,8644} \\
\hline & $X_{32}$ & 0,6066 & \\
\hline & $X_{33}$ & 0,7500 & \\
\hline & $X_{34}$ & 0,6788 & \\
\hline \multirow[t]{2}{*}{$\overline{X_{4}}$} & $X_{41}$ & 0,762 & \multirow[t]{2}{*}{0,8632} \\
\hline & $X_{42}$ & 0,762 & \\
\hline
\end{tabular}

Dapat diparhatikan Tabel 2. nilai $r_{\text {hitung }}>0,361$ untuk semua indikator pertanyaan, artinya semua indikator pertanyaan dinyatakan valid. Sedangkan untuk nilai Cronbach's Alpha dapat diperhatikan bahwa semua nilainya > 0,7 pada masing-masing variabel, yang artinya bahwa instrumen atau kuesioner tersebut reliabel atau layak digunakan.

\subsection{Analisis Korelasi}

Mengamati korelasi antar indikator pada masing-masing variabel dengan memeriksa nilai Bartlett's sphericity. Dengan taraf signifikansi yang digunakan sebesar $5 \%$, kriteria nilai yang signifikan yaitu sig. $<0,05$. Dengan menggunakan softw are SPSS diperoleh nilai Bartlett's sphericity yang sama pada keempat variabel yaitu sebesar $0,00<0,05$, artinya bahwa terdapat korelasi atau hubungan antar indikator pada masing-masing variabel.

\subsection{Proses Analisis Komponen Utama}

Analisis komponen utama dilakukan terhadap indikator pada masing-masing variabel, dengan tujuan mereduksi indikator sehingga diperoleh peubah baru yang merupakan kombinasi linear dari indikator tersebut.

1. Variabel sarana dan prasarana

$$
\mathrm{K}_{1}=0,553 \mathrm{X}_{11}+0,599 \mathrm{X}_{12}+0,580 \mathrm{X}_{13}
$$

2. Variabel perencanaan pembelajaran

$$
K_{2}=0,573 X_{21}+0,613 X_{22}+0,544 X_{23}
$$


3. Variabel proses pembelajaran

$K_{3}=0,508 X_{31}+0,435 X_{32}+0,530 X_{33}$ $+0,521 X_{34}$

4. Variabel penilaian pembelajaran

$$
K_{4}=0,707 X_{41}+0,707 X_{42}
$$

\subsection{Peta Kendali Individu-Moving Range (I-MR)}

Berdasarkan jawaban responden pada masing-masing indikator kualitas pembelajaran dilakukan pengamatan dengan membuat peta kendali individual-moving range. Perlu diperhatikan bahwa penelitian ini berdasarkan jawaban responden atau menurut persepsi mahasiswa.

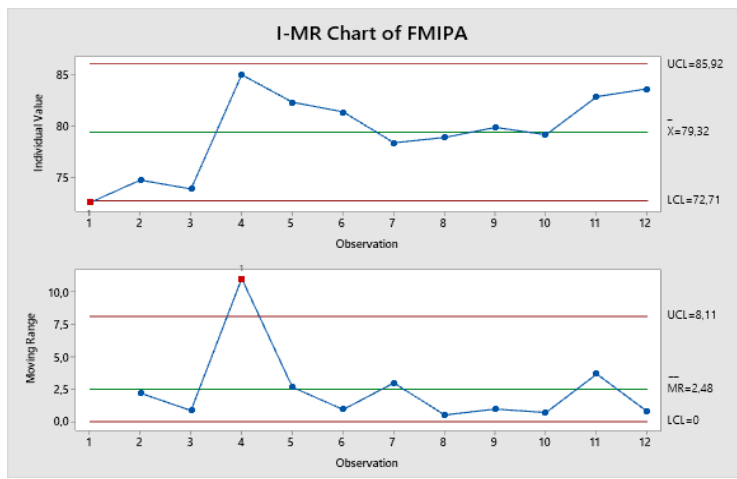

Gambar 1. Peta kendali I-MR Kualitas Pembelajaran di Fakultas MIPA

Dapat diperhatikan Gambar 1. menunjukkan tingkat kualitas pembelajaran di Fakultas MIPA tidak terkendali, karena terdapat satu indikator yang berada di luar batas kendali baw ah $(\mathrm{LCL}=72,71)$. Indikator tersebut yaitu ketersediaan fasilitas pendukung pembelajaran, perlu tindakan peningkatan kualitas ketersediaan fasilitas pendukung pembelajaran untuk menunjang proses pembelajaran di Fakultas MIPA. Gambar 1 juga menunjukkan nilai jarak atau selisih antar indikator, dimana terdapat selisih yang melonjak hingga berada di luar batas kendali atas yaitu selisih antara sistem informasi layanan administrasi dengan penyampaian kontrak perkuliahan oleh dosen.

\subsection{Uji Normal Multivariat}

Asumsi dasar yang harus dipenuhi dalam membuat peta kendali multivariat adalah uji distribusi normal multivariat. Menurut Johnson \& Wichern (2007), distribusi normal multivariat data dapat dilihat dari plot $\left(d_{i}^{2}\right)$ dengan chi-square $\left(q_{i}\right)$. Jika hasil scatter-plot menunjukkan terdapat lebih dari $50 \%$ yang memiliki nilai $d_{i}^{2} \leq \chi_{12: 0,5}^{2}$ dapat disimpulkan bahwa data berdistribusi normal multivariat.

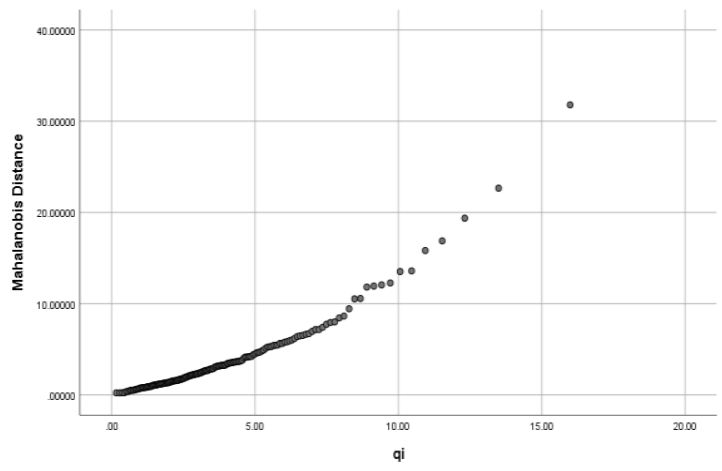

Gambar 2. Scatter-plot

Pada Gambar 2. terlihat bahwa titik-titik pada scatter-plot cenderung membentuk garis lurus atau mengikuti garis normal. Dengan bantuan software SPSS diperoleh hasil bahwa terdapat $81,8 \%$ yang menunjukkan nilai $d_{i}^{2} \leq$ $\chi_{12: 0,5}^{2}$. Sehingga dapat disimpulkan bahwa data berdistribusi normal multivariat.

\subsection{Peta Kendali $\mathrm{T}^{2}$}

Nilai taksiran komponen utama yang diperoleh dari analisis komponen utama akan dibuat peta kendali multivariat menggunakan peta kendali $\mathrm{T}^{2}$. Digunakan software Minitab19 untuk membuat peta kendali multivariat dari keempat komponen utama, sehingga diperoleh hasil seperti pada Gambar 3.

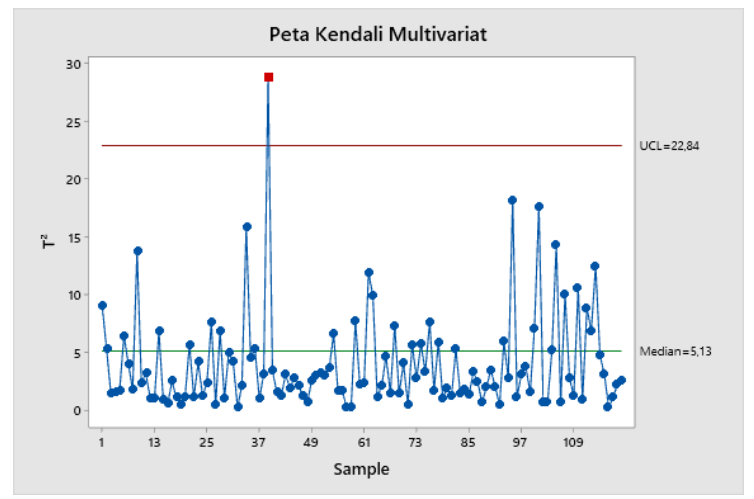

Gambar 3. Peta Kendali Kualitas Pembelajaran di Fakultas MIPA

Perhatikan Gambar 3. yang menunjukkan tingkat kualitas pembelajaran di Fakultas MIPA. Terdapat satu pengamatan yang berada di luar batas kendali atas $(\mathrm{UCL}=22,84)$ yaitu pengamatan ke-39. Hal ini menunjukkan bahwa responden ke-39 memberikan penilaian tinggi terhadap kualitas pembelajaran di Fakultas MIPA. 


\section{SIMPULAN DAN SARAN}

Berdasarkan uraian hasil dan pembahasan, maka diperoleh simpulan bahwa indikator kualitas pembelajaran dapat direduksi menggunakan analisis komponen utama, sehingga diperoleh peubah baru yang merupakan kombinasi linear dari indikator tersebut. Hasil yang diperoleh menunjukkan kontribusi dari indikator kualitas pembelajaran yang tidak merata. Potret kualitas pembelajaran di Fakultas MIPA pada peta kendali individual-moving range (I-MR) menunjukkan bahwa terdapat satu indikator yang berada di luar batas kendali bawah yaitu ketersediaan fasilitas pendukung pembelajaran. Potret kualitas pembelajaran yang diperoleh dari peta kendali $\mathrm{T}^{2}$ menunjukkan terdapat satu pengamatan yang berada di luar batas kendali atas (UCL $=22,84)$ yaitu pengamatan ke-39. Hal ini menunjukkan bahwa responden ke-39 memberikan penilaian tinggi terhadap kualitas pembelajaran di Fakultas MIPA. Kualitas pembelajaran perlu ditingkatkan dengan melakukan tindakan perbaikan dan pemantauan berkala.

Penelitian ini menggunakan peta kendali individual-moving range untuk pengamatan individu dan peta kendali $\mathrm{T}^{2}$ dengan jumlah variabel lebih dari satu. Sehingga untuk kajian lebih lanjut perlu dilakukan dengan menggunakan metode kendali mutu yang lainnya seperti peta kendali rata-rata $(\overline{\mathrm{X}})$ dan range $(\mathrm{R})$ disertai penambahan variabel dan indikator kualitas pembelajaran yang lebih banyak dari sektor yang berbeda.

\section{DAFTAR PUSTAKA}

Andayani, S., Hidayati, K., \& Sahid. (2007). Peningkatan Kualitas Pembelajaran Pemrograman Komputer Melalui Perkuliahan Online Pada Mahasiswa Program Studi Pendidikan Matematika FMIPA Universitas Negeri Yogyakarta. Pythagoras: Jurnal Pendidikan Matematika, Vol. 3(1), 15-28.

Damayanti, N., Goejantoro, R., \& Wasono (2016). Pengendalian Kualitas Produk Menggunakan Peta Kendali $\mathrm{T}^{\wedge} 2$ Hotelling dan Analisis Kemampuan Proses Untuk Data Multivariat dengan Pengamatan Individual. Prosiding Seminar Sains Dan
Teknologi FMIPA Unmul, 535-539.

Hair Jr, J. F., Black, W. C., Babin, B. J., Anderson, R. E., Black, W. C., \& Anderson, R. E. (2019). Multivariate Data Analysis (Eighth Edi). Annabel Ainscow. https://doi.org/10.1002/9781119409137.ch 4

Haramain, M., Nurhikmah, \& Wahidin, A. (2019). Strategi Program Studi dalam Meningkatkan Standar Mutu Akreditasi (H islamul Haq (ed.)). IAIN Parepare Nusantara Press.

Johnson, R. A., \& Wichern, D. W. (2007). Applied Multivariate Statistical Analysis (Fifth Edit). Prentice Hall.

Montgomery, D. C. (2012). Introduction to Statistical Quality Control (Seventh Ed). Wiley.

Ryan, T. P. (2013). Sample Size Determination and Power. In Sample Size Determination and Power. https://doi.org/10.1002/9781118439241

Tabachnick, B. G., Fidell, L. S., Kingdon, G. G., Hays, W. L., Dutta, T., Mandal, M. K., Sauter, R. M., \& Research, E. (2018). Using multivariate statistics / Barbara G. Tabachnick, Linda S. Fidell. In Contemporary Psychology: A Journal of Reviews (Vol. 28, Issue 1).

Peraturan BAN-PT No.3 Tahun 2019 tentang Instrumen Akreditasi Perguruan Tinggi 